\title{
BMJ Open Hospitalisation cost analysis on hip fracture in China: a multicentre study among 73 tertiary hospitals
}

\author{
Yilin Wang, Haoran Cui, Dianying Zhang, Peixun Zhang
}

To cite: Wang Y, Cui H, Zhang D, et al. Hospitalisation cost analysis on hip fracture in China: a multicentre study among 73 tertiary hospitals. BMJ Open 2018;8:e019147. doi:10.1136/ bmjopen-2017-019147

- Prepublication history and additional material for this paper are available online. To view these files, please visit the journal online (http://dx.doi.org/)

Received 16 August 2017

Revised 28 March 2018

Accepted 29 March 2018
Check for updates

Department of Traumatic Orthopedics, Peking University People's Hospital, Beijing, China

\section{Correspondence to}

Dr Dianying Zhang;

zdy8016@163.com and Dr

Peixun Zhang;

zhangpeixun@bjmu.edu.cn

\section{ABSTRACT}

Objective To describe and analyse the hospitalisation cost of patients with hip fracture under the influence of various factors and to provide references for Chinese national medical insurance policy.

Materials and methods All data were collected from the Chinese National Medical Data Centre database, which contained the hospitalisation data of 73 tertiary hospitals from 24 provinces. The included patients were first hospitalised with the main diagnosis of femoral neck or intertrochanteric fracture, and were discharged between 1 January 2014 and 31 December 2015. Secondary hospitalisation, multiple trauma or pathologic fracture (except for osteoporotic fracture) patients or patients with missing data were excluded. The impact of various factors on the cost was investigated using analysis of variance and multivariable linear regression analysis. The Gross Domestic Product per capita and average annual disposable income were obtained from the website of the National Bureau of Statistics.

Results 27205 cases were included in the study. The mean cost of all patients was $¥ 53440$. 60-69 years age group had a significantly higher cost compared with 80 years and above age group. The mean cost of femoral neck fractures was lower than that of the patients with intertrochanteric fractures; the mean cost of hip replacement was higher than that of internal fixation, which showed a strong effect of the surgical approach to the cost. Patients in low-income provinces spent less than those in high-income provinces, while the gap between high-income and middle-income provinces were relatively small.

Conclusion The hospitalisation cost of hip fracture has become a great burden to the patients' families. The Chinese medical insurance policy may need further consideration of the demographic and economic factors.

\section{INTRODUCTION}

Hip fractures are common, especially for the elderly patients. As the elderly population grows, the number of hip fractures continues to increase. ${ }^{1}$ Elderly adults had over 2.1 million emergency department visits for injurious falls in 2006 in the USA, and hip fractures accounted for about one in eight injurious fall-related emergency department visits among the elderly. ${ }^{2}$ Worldwide,

\section{Strengths and limitations of this study}

This study was the first multicentre study to analyse the cost of hip fracture in China with a large sample of 27205 cases covering 73 tertiary hospitals in 24 provinces including all age groups.

- This study compared the cost with the Gross Domestic Product per capita and average income, focused on patients' economic burden and could serve as a reference for relevant Chinese national insurance policy.

- Selection bias existed, 73 hospitals were only $3.6 \%$ of all tertiary hospitals and 3 hospitals on average for each province were not representative. Thus, the conclusion on the differences between provinces and representativeness for the whole nation cannot be made. More comprehensive programme with standard sampling method is needed to provide a more systematic and elaborate view.

- The data of medical insurance condition of each patient were not available in the database, and the out-of-pocket costs cannot be calculated. The direct economic burden on the patients still needs further investigation.

- Although the malignant fracture and multiple trauma had been excluded from the study, there were still some patients with different complications after the admission to the hospital, which potentially increased the hospitalisation cost. Further study should be carried on to better control the impact of complications.

total number of hip fractures is expected to surpass 6 million by the year 2050. ${ }^{3}$ In adults younger than 50 years of age, some hip fractures occurred in men after high-energy injuries, and some happened in patients who were medically frail or had osteoporosis. ${ }^{4}$ Although there had been a marked decrease of hip fracture incidence in younger population in Germany, ${ }^{5}$ few studies discussed the situation and trend in China.

The medical cost of hip fracture has become a great burden to the patients' families, and to the medical system because of its high morbidity and huge treatment expense. ${ }^{6}$ A Germany research in 2007 showed that the 
mean hospitalisation cost of patients who received hip replacement was $€ 7000,{ }^{7}$ and another Irish study in 2008 showed the mean cost of patients with hip fracture was about for $€ 9236 .{ }^{8}$ There also exists related research in China. For example, a retrospective study for 10 years (1998-2007) in Guangzhou pointed out that the mean hospitalisation cost of local patients with hip fracture is $¥ 23000 .{ }^{9}$

China is a large developing country facing population-ageing problem, with economic and medical conditions highly different among regions. Several researches in Beijing, ${ }^{10}$ Shenyang, ${ }^{11}$ Tangshan ${ }^{12}{ }^{13}$ and Hefei ${ }^{14}$ revealed an increasingly high incidence of osteoporotic hip fractures. And several projections have been made based on these researches that the osteoporotic hip fracture incidence would surpass 1000 per 100000 people in the population aged over 50 years. ${ }^{15-17}$ Moreover, the cost of hip fractures is the highest among all types of osteoporotic fractures in China, ${ }^{17}$ and will put more economic burden on patients' families. Meanwhile, hip fractures of young population could result in direct loss of productivity. The 10-year mortality rate of young patients with hip fracture was as high as $10.5 \%$, and the 10-year standardised mortality ratio was 5.82 in a recent Taiwan study. ${ }^{18}$

However, there was seldom epidemiology study of hip fracture covering all age groups on a national scale, neither little multicentre study on the cost of hip fractures hospitalisation in China, nor any assessment of the economic conditions of the patients. On the other hand, there is relatively little private medical insurance in China and the public medical insurance policy keeps on reforming over time. The public medical insurance reimburses are different in every province, and varies depending on the total hospitalisation costs. Nevertheless, Chinese medical insurance policy needs further enhancement.

The aim of this study was to describe and analyse the hospitalisation cost of patients with hip fracture under the influence of various factors, and to provide references for Chinese national medical insurance policy.

\section{MATERIALS AND METHODS}

\section{Study design}

This is a cross-sectional analysis of a nationwide database in China.

\section{Data source}

The hospitalisation data of patients with hip fracture were analysed from the Chinese National Medical Data Centre database from 1 January 2014 to 31 December 2015. The database is a nationwide health information system established by the National Health and Family Planning Commission of People's Republic of China and Peking University Health Science Center, containing all the medical data of 73 tertiary hospitals from 24 provinces during 2014-2015. China has a total of 2026 tertiary hospitals across 34 provinces. Thus, this study included patients from only $3.6 \%$ of tertiary hospitals in China. The Gross Domestic Product (GDP) per capita and average annual disposable income were obtained from the website of the National Bureau of Statistics. ${ }^{19}$

\section{Study population}

By searching the Chinese National Medical Data Centre database, all the patients with the main diagnose of femoral neck (International Classification of Disease-10 code S72.0) or intertrochanteric fracture (ICD-10 code S72.1) among all age groups were available. The included patients were first hospitalised with the main diagnosis of femoral neck or intertrochanteric fracture, and were discharged between 1 January 2014 and 31 December 2015. Their hospitalisation cost, ages on fracture, diagnoses, treating methods, hospitalisation provinces and length of stay were gathered. Patients missing of any of the data above or secondary hospitalisation patients were excluded, patients with multiple trauma or pathologic fracture (except for osteoporotic fracture) were also excluded.

\section{Outcome measurements}

Study factors measured were the patients' diagnosis, treatment type, age, hospitalisation province and length of hospital stay as well as hospitalisation cost. The cost means the total direct medical cost of patients' first hospitalisation.

\section{Statistical analysis}

All the patients were divided into several groups according to their ages, diagnoses, treating methods and hospitalisation provinces, analysed using SPSS V.23.0. The impact of various factors on the cost of hospitalisation was investigated using analysis of variance (ANOVA). Multiple linear regression analysis was used to model predictors of total hospital costs. The independent variables were length of hospital stay, age, diagnosis, treatment methods and income levels. The age groups were divided into five intervals, including below 50, 50-59, 60-69, 70-79, $80-89$ years and 80 years and above groups. Because most patients cluster in the 80 years and above interval, this interval was set as a reference group, with the introduction of four dummy variables. In addition, the patients were divided into three types according to their treatment methods: fracture reduction and internal fixation, hip replacement, conservative treatment and other treatment. Two dummy variables were introduced, and the fracture reduction and internal fixation was used as the reference group. A dummy variable was introduced to the diagnosis with intertrochanteric fractures as a reference group. The income levels were divided to three grades according to the disposable income level of different provinces (see online supplementary table 1 ). Patients in the eight highest income provinces were grouped into high-income level, and those in the eight lowest income provinces were grouped into low-income, otherwise were middle-income. Two dummy variables were introduced, 


\begin{tabular}{|c|c|}
\hline Characteristics & $\mathbf{N}(\%)$ \\
\hline \multicolumn{2}{|l|}{ Age (years) } \\
\hline$<50$ & $2732(10.0)$ \\
\hline $50-59$ & $2620(9.6)$ \\
\hline $60-69$ & $4441(16.3)$ \\
\hline $70-79$ & $7819(28.7)$ \\
\hline$\geq 80$ & $9593(35.3)$ \\
\hline \multicolumn{2}{|l|}{ Diagnosis } \\
\hline Intertrochanteric fracture & $10636(39.1)$ \\
\hline Femoral neck fracture & $16569(60.9)$ \\
\hline \multicolumn{2}{|l|}{ Treatments } \\
\hline Internal fixation & $11531(42.4)$ \\
\hline Hip replacement & $12527(46.0)$ \\
\hline Other treatments & 3147 (11.6) \\
\hline
\end{tabular}

and high-income level group was reference group. The model was derived using a backward method. The level of significance was all set at $\mathrm{P}<0.05$. Meanwhile, the choropleth maps of the hospitalisation cost, GDP per capita and disposable income was made using Excel 2007 to describe the distribution characteristics.

\section{PATIENTS AND PUBLIC INVOLVEMENT}

Patients and public were not involved in this study.

\section{RESULTS}

\section{Basic conditions of the patients}

A total of 27205 patients were included in the study. The patients aged from 1 to 106 years, with the mean age 71.27
$(\mathrm{SD}=16.52)$. Table 1 shows the frequency and proportions of patients by age group, diagnosis and treatment.

\section{Hospitalisation cost and length of hospital stay}

The mean treatment cost of all patients was $¥ 53440$ ( $\mathrm{SD}=¥ 35238$ ), higher than the GDP per capita in 2014 (¥46 629), which was 2.65 times of the disposable income per capita in 2014 (¥20 167). Table 2 shows the mean hospitalisation cost by age group, diagnosis and treatment. There were significant differences in hospitalisation costs between age groups $(\mathrm{F} 4,27200=159.03 ; \mathrm{P}<0.001)$, diagnoses $(\mathrm{F} 1,27203=21.32 ; \mathrm{P}<0.001)$ and treatment type (F2, 27 202=708.66; $\mathrm{P}<0.001$ ).

The mean length of hospital stay was 14.8 days ( $\mathrm{SD}=11.86$ days). Table 2 shows the mean hospital days by age group, diagnosis and treatment. There were significant differences in hospitalisation costs between age groups (F4, $27 \quad 200=44.0 ; \quad \mathrm{P}<0.001)$, diagnoses $(\mathrm{F} 1,27203=6.10 ; \mathrm{P}<0.001)$ and treatment type $(\mathrm{F} 2$, 27 202=147.57; $\mathrm{P}<0.001$ ).

As shown in table 3 , the diagnosis, treatments, age groups, income levels and length of hospital stay were all predictors of hospitalisation cost. The mean cost was lowest for the $<50$ years age group and highest for those aged 70-79years as shown in table 2; however, table 3 shows 60-69years age group as a predictor of higher mean cost than $\geq 80$ years group $(\mathrm{T}=7.202, \mathrm{P}<0.001)$. The mean cost of femoral neck fractures was lower than intertrochanteric fractures $(\mathrm{T}=-30.559, \mathrm{P}<0.001)$; the mean cost of hip replacement was higher than internal fixation ( $\mathrm{T}=46.535, \mathrm{P}<0.001)$, which showed a strong effect of the surgical approach to the cost. The hospitalisation cost increased with the increase of every hospital day $(\mathrm{T}=115.479, \mathrm{P}<0.001)$. Patients in low-income provinces spent less than high-income provinces $(\mathrm{T}=-13.081$, $\mathrm{P}<0.001$ ), while the gap between high-income and

Table 2 Descriptive statistics on total hospital costs and length of stay of patients with hip fracture

\begin{tabular}{|c|c|c|c|c|}
\hline \multirow[b]{2}{*}{ Characteristics } & \multicolumn{2}{|c|}{ Total hospital costs ( $¥)$} & \multicolumn{2}{|c|}{ Length of hospital stay (days) } \\
\hline & Mean & SD & Mean & SD \\
\hline \multicolumn{5}{|l|}{ Age (years) } \\
\hline$<50$ & 40361 & 33701 & 13.4 & 11.8 \\
\hline $50-59$ & 45864 & 28987 & 13.2 & 9.3 \\
\hline $60-69$ & 55016 & 28364 & 14.1 & 8.8 \\
\hline $70-79$ & 55490 & 28731 & 15.2 & 13.9 \\
\hline$\geq 80$ & 53440 & 35238 & 14.8 & 11.8 \\
\hline \multicolumn{5}{|l|}{ Diagnosis } \\
\hline Intertrochanteric fracture & 54670 & 37420 & 15.1 & 11.1 \\
\hline Femoral neck fracture & 52649 & 33740 & 14.7 & 12.2 \\
\hline Internal fixation & 45948 & 34572 & 13.4 & 10.0 \\
\hline \multicolumn{5}{|l|}{ Treatments } \\
\hline Hip replacement & 61919 & 25988 & 16.0 & 9.1 \\
\hline Other treatments & 47138 & 56000 & 15.2 & 22.3 \\
\hline Total & 53440 & 35238 & 14.8 & 11.8 \\
\hline
\end{tabular}


Table 3 Multivariable analysis of total hospital costs for patients with hip fracture

\begin{tabular}{|c|c|c|c|c|}
\hline \multirow[b]{2}{*}{ Predictor } & \multicolumn{2}{|c|}{ Index hospitalisation cost ( $¥)$} & \multirow{2}{*}{$\begin{array}{l}\text { T value } \\
(\mathrm{df}=27198)\end{array}$} & \multirow[b]{2}{*}{$P$ value } \\
\hline & Parameter estimate & $95 \% \mathrm{Cl}$ & & \\
\hline \multicolumn{5}{|l|}{ Final } \\
\hline Intercept & 28450 & (27732 to 29 168) & 77.646 & 0.000 \\
\hline \multicolumn{5}{|l|}{ Diagnosis } \\
\hline $\begin{array}{l}\text { Femoral neck } \\
\text { fracture }\end{array}$ & -12818 & $(-13640$ to -11995$)$ & -30.559 & 0.000 \\
\hline $\begin{array}{l}\text { Intertrochanteric } \\
\text { fracture }\end{array}$ & Reference & Reference & Reference & Reference \\
\hline $\begin{array}{l}\text { Length of hospital } \\
\text { stay }\end{array}$ & 1648 & (1620 to 1676$)$ & 115.479 & 0.000 \\
\hline \multicolumn{5}{|l|}{ Age groups (years) } \\
\hline $60-69$ & 3279 & (2387 to 4172 ) & 7.202 & 0.000 \\
\hline$\geq 80$ & Reference & Reference & Reference & Reference \\
\hline \multicolumn{5}{|l|}{ Treatments } \\
\hline Hip replacement & 19225 & (18415 to 20035 ) & 46.535 & 0.000 \\
\hline Internal fixation & Reference & Reference & Reference & Reference \\
\hline \multicolumn{5}{|l|}{ Income levels } \\
\hline Middle-income & -793 & $(-1577$ to -9$)$ & -1.984 & 0.047 \\
\hline Low-income & -6490 & $(-7462$ to -5517$)$ & -13.081 & 0.000 \\
\hline High-income & Reference & Reference & Reference & Reference \\
\hline
\end{tabular}

middle-income provinces were relatively small $(\mathrm{T}=-1.984$, $\mathrm{P}=0.047)$.

The model was derived using a backward method and has an $\mathrm{R}^{2}$ of 0.386 . All variables were included at the significance of $5 \%$ level. The intercept value of $¥ 28450$ should be interpreted as the mean hospitalisation cost of intertrochanteric patients from high-income provinces aged 80 years and above receiving internal fixation with 0 day of hospital stay.

\section{GDP, disposable income and hospitalisation cost}

As shown in online supplementary table 2, ANOVA shows a significant difference in the distribution of hospital cost between different provinces (F23, 27 181=26.58, $\mathrm{P}<0.001)$. The choropleth maps were plotted based on the data in online supplementary table 1 , as is shown in figure 1. Figure 2 and figure 3 show China's GDP per capita distribution and the distribution of disposable income per capita in 2014, respectively. Comparing these three figures, the difference of distribution between figure 1 and figure 2 and 3 can be observed. Based on the data from supplementary table 1, a Pearson's correlation is done to analyse the correlation between mean costs, annual disposable income and GDP per capita in different provinces. The correlation between GDP and income is significant at $\mathrm{P}<0.001$, with the Pearson's correlation coefficient 0.906 . However, neither GDP nor income shows significant correlation with hospitalisation cost (see online supplementary table 3 ).

\section{DISCUSSION}

This is the first nationwide multicentre study of the cost of hip fractures in China among all age groups. The study started with the concern regarding economic burden on patients with hip fracture, and is expecting more attention from Chinese government, calling for the general population and policymakers paying more attention to osteoporosis and related medical insurance policy.

In China, a majority of patients choose to receive primary treatment in a tertiary hospital due to the special national condition. There were 2026 tertiary hospitals in China by $2015 .{ }^{20}$ By assuming all patients with hip fracture went to tertiary hospitals to receive primary treatment, and all tertiary hospitals shared all patients averagely, it is roughly estimated that the patients proportion of all patients with hip fracture in China was 73 in 2026, which equalled $3.6 \%$. However, this proportion was overestimated. The vast majority of patients chose to rest at home in rural areas, ${ }^{1517}$ and a minor proportion of patients would go to primary or secondary hospitals. The selection of 73 hospitals was not based on any sampling method and the hospitals only occupied $3.6 \%$ of all tertiary hospitals, thus selection bias existed and the conclusion on the representativeness for the whole nation and the differences between provinces cannot be made. However, this database was already the most comprehensive and generalisable hip fracture database in China at the present time. This study described the imbalances between hospitalisation cost and income level in these available samples, and 


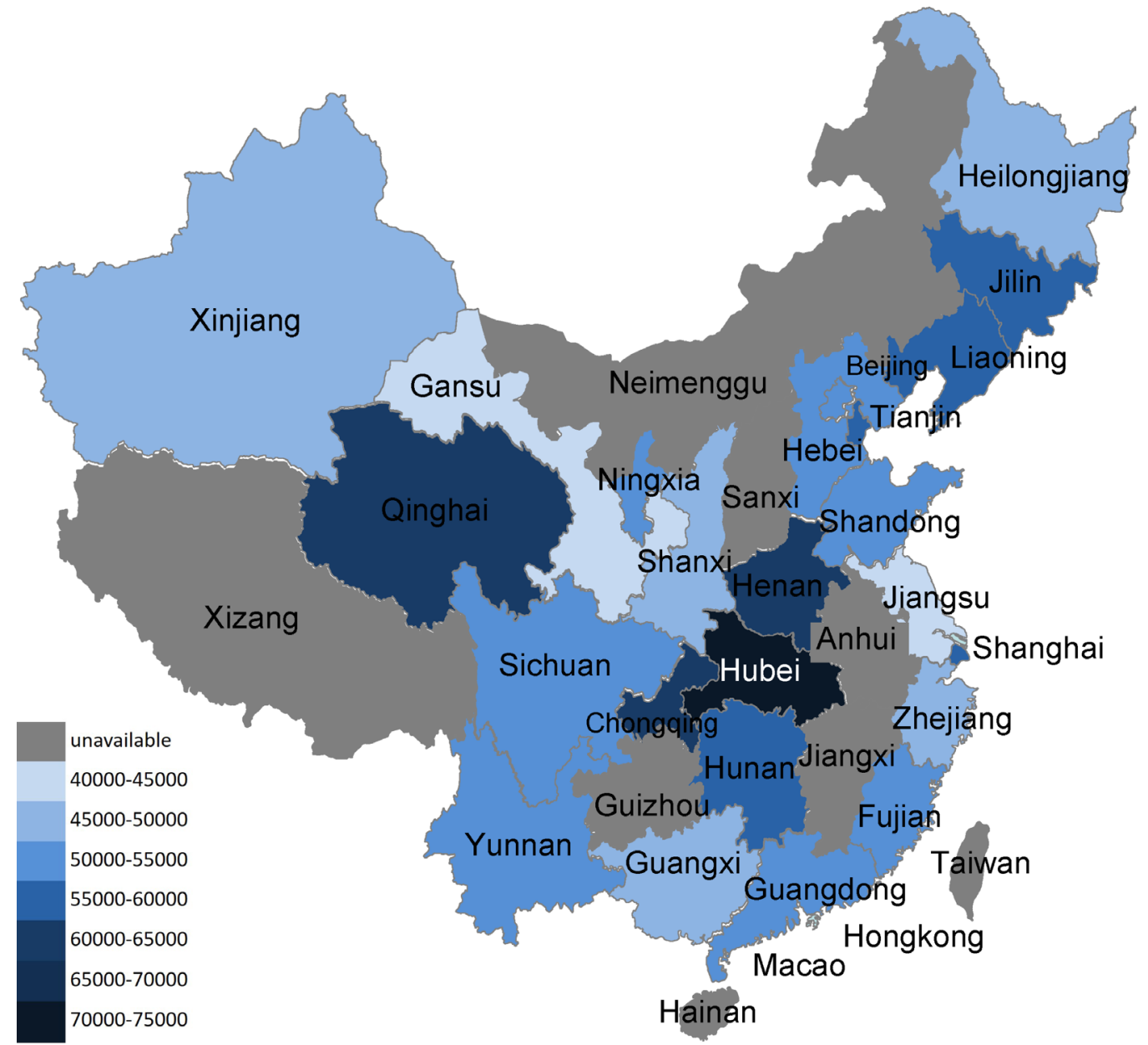

attempted to reflect the potential differences between provinces. The study also calls for more comprehensive programme with standard sampling method to provide a more systematic and elaborate view.

The costs in this research were the total direct hospitalisation costs of first hospitalisation, not including the rehabilitation costs, and were provided by hospitals. Because the insurance information of every patient cannot be achieved, the out-of-pocket costs cannot be calculated either, the direct economic burden on the patients still needs further investigation. On the other hand, although the malignant fracture and multiple trauma had been excluded from the study, there were still some patients with different complications after the admission to the hospital, which potentially increased the hospitalisation cost. Further study should be carried on to better control the influence of complications.

Reports from the USA showed that the prevalence of osteoporosis was around 54\% in elder adults, affecting approximately 53.6 million in $2010,{ }^{21}$ which is estimated to increase continually. ${ }^{22}$ Hip fractures are common, especially for the elderly patients because of a higher incidence of osteoporosis. ${ }^{2324}$ They account for the majority of fracture-related healthcare cost, in other words, they can be used to determine the economic burden of osteoporosis as a useful surrogate. ${ }^{24}$ Although in Asia, the incidence is lower compared with other countries in Europe or America, especially in Mainland China, ${ }^{25}$ it has increased and will increase continually because of the increasingly higher ratio of older people, which is associated with the improvement of the life expectancy. ${ }^{10} 131417$ Hip fracture had always been the most expensive fracture among all osteoporotic fractures in China, ${ }^{15} 17$ and the mean hospitalisation cost has rose up to $¥ 53440$, which almost doubled the cost from the former Chinese study. ${ }^{1517}$ The mean cost of our study is higher than Lithuania $(€ 2526.7,2010),{ }^{26}$ and is almost the same level with South Korean (US\$8302, 2011), ${ }^{27}$ while lower than the USA (US\$12 100, 2006). ${ }^{28}$ However, these comparisons are meaningless without comparing the GDP and income. Knowing from the Ministry of Health ${ }^{29}$ China Health Yearbook that the percentage of total health expenditure to GDP was $5.15 \%$, the ratio reflected in this study is far beyond the expectation. ${ }^{29}$ Additionally, the development of different provinces in China is dramatically unbalanced, an analysis on different impacts on hip fracture costs is imperative. This study would help to describe the present status and propose for the 


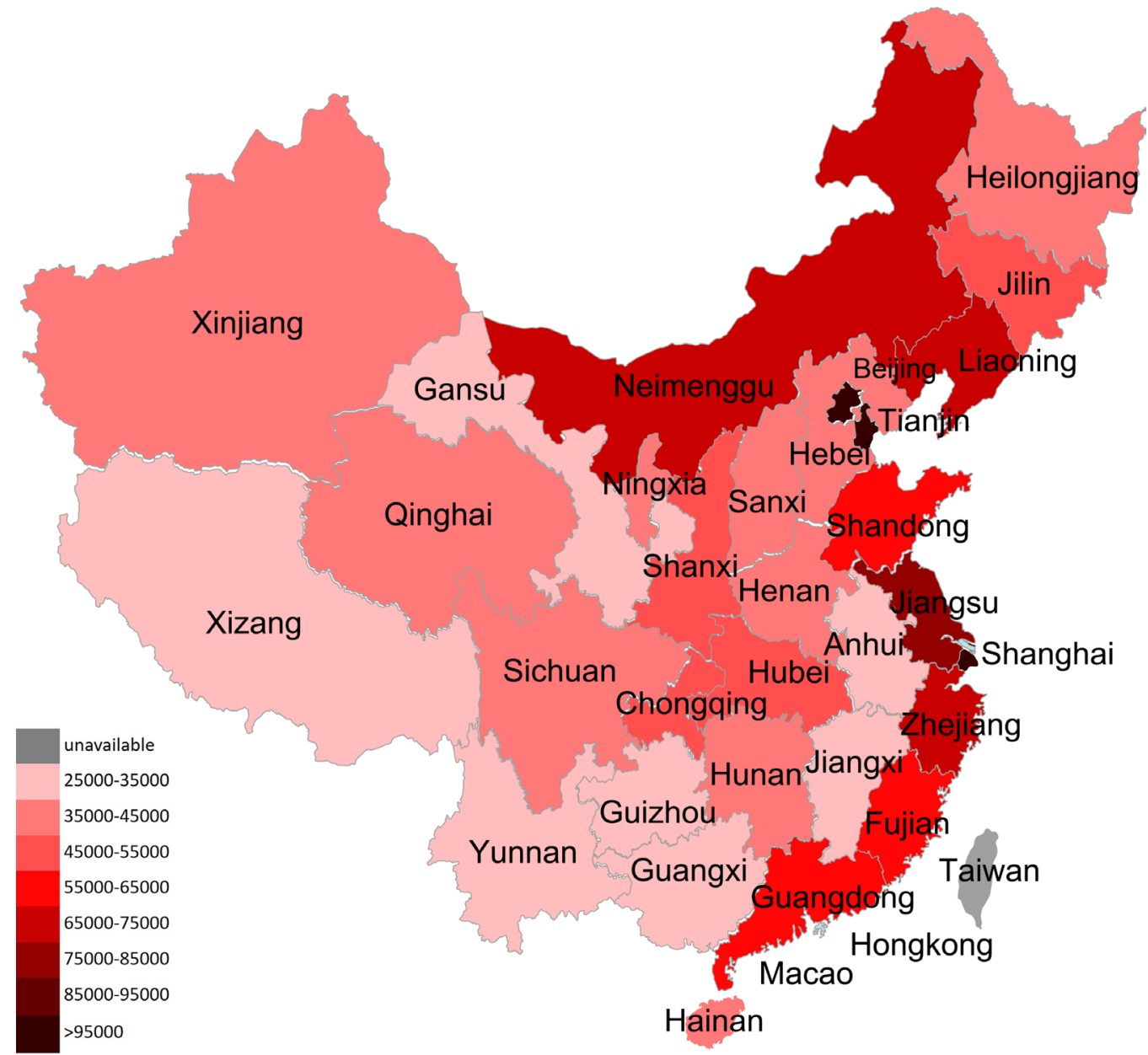

Figure 2 The regional distribution of China's Gross Domestic Product (GDP) per capita in 2014. Grey colour indicates that data are unavailable or not applicable and red area from light to dark indicates the regional distribution of China's GDP per capita in 2014, which was obtained from the website of National Bureau of Statistics of the People's Republic of China. The unit is $¥$. In 2014, China's GDP per capita was $¥ 46629$.

government regulation on the healthcare and medical insurance policy.

\section{The impact of various influence factors on hospital length of} stay and hospitalisation cost

Patients in the 80 years and above age group had the highest case number of hip fracture, which might be explained by the fact that osteoporosis became more severe as the patient grew older. As a result, the case number of hip fractures increased significantly with age. However, multiple regression analysis showed that there was a significantly higher cost in 60-69years age group than the reference group. The surgical approach-internal fixation, was commonly applied for young patients or patients too old to accept hip replacement in clinical practice, thus the cost of which was lower compared with hip replacement. The reason needs further proof and investigation.

The mean hospitalisation cost of intertrochanteric fractures was significantly higher than that of femoral neck fractures, which was also confirmed by multiple linear regression. The reason might be the use of more expensive proximal femoral nail antirotation instruments in internal fixation surgery of the intertrochanteric fractures compared with dynamic hip screw of femoral neck fracture.

The patients were divided into three groups according to their treatment methods in this study: internal fixation, hip replacement as well as conservative treatment and other treatment. The last group included a variety of treatments, such as bone traction, external fixation and other conservative treatments, which was not further subdivided due to the diversity of treatment types. This group accounted for only a minority in the total cases $(11.6 \%)$, with cost being slightly more than internal fixation and less than hip replacement patients. The data discretisation of their hospitalisation cost and length of stay was large, and thus difficult to analyse. However, the mean cost of this group was higher than that of internal fixation, which might be due to the fact that these patients had more complications. The number of patients who underwent fracture reduction and internal fixation was similar to the number of patients with hip replacement, and the mean cost of hospitalisation was significantly lower than the latter, which could be due to the differences in the cost of surgical supplies. 


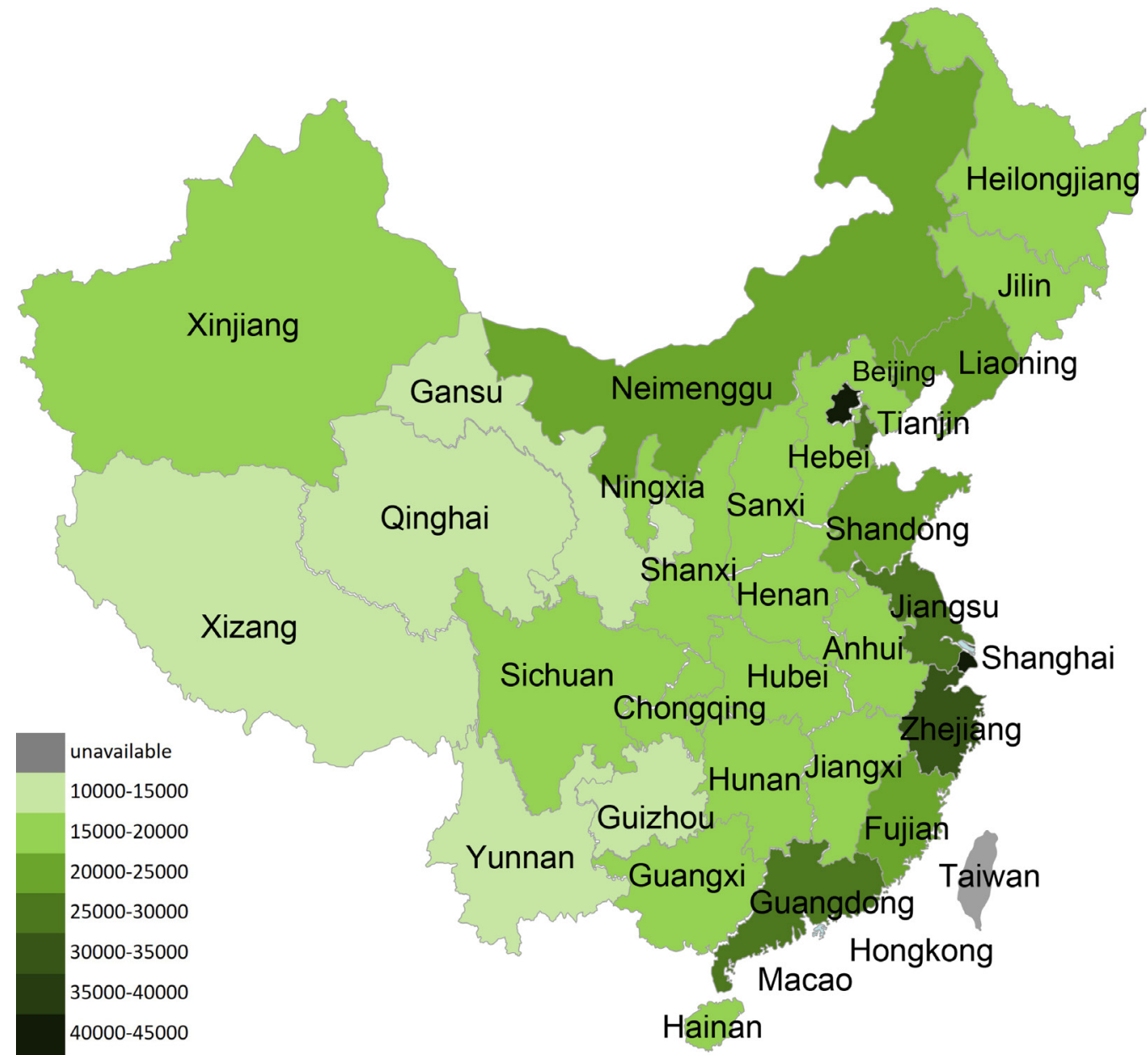

Figure 3 The distribution of disposable income per capita in China in 2014. Grey colour indicates that data are unavailable or not applicable, and green from light to dark indicates the disposable income per capita in China in 2014, obtained from the website of National Bureau of Statistics of the People’s Republic of China, which was 20167 with the unit $¥$.

\section{GDP, disposable income and mean hospitalisation cost in different provinces}

The correlation analysis showed no correlation between cost with income or GDP. However, the multiple linear regression analysis revealed differences among high-income, middle-income and low-income level provinces. The low absolute value of parameter estimated of middle-income provinces might still reveal the unbalanced development of Chinese economy and healthcare. The distribution of cost did not show any vertical or horizontal distribution patterns, but a radiation pattern around several centres. Areas with higher hospitalisation cost were located in Hubei, Beijing, Shanghai and Qinghai provinces, because there were larger medical centres in these regions. Thus, a higher level of regional medical development could lead to higher treatment cost. The distributions of GDP per capita and disposable income per capita were consistent, following the distribution law of 'higher in the East, followed by the middle, and lower in the West'. The difference between this distribution and the mean hospitalisation cost implied that the patients in some parts of the Midwest regions had lower annual income yet with higher mean hospitalisation cost on hip fractures. In some areas, the patient might spend several times of their annual disposable income per capita to treat a hip fracture, which could exert huge financial burdens on their family. Although bias existed in the selection of hospitals and the conclusion on the representativeness for the whole nation cannot be made, the difficult situation was certain for these selected samples.

There is relatively little private medical insurance in China. The medical insurance mainly means the public medical insurance offered by Chinese government, whose reimburses are different in every province, and varies depending on the total hospitalisation costs. The policies are also different in different provinces, and are reforming frequently. A patient could only consult the reimburses in the local medical insurance department, thus there are no specific data available for those reimburses on the internet. The only information available is that the government's overall anticipation of reimburses through the government reports was $75 \%,{ }^{30}$ and the proportion of total personal health expenditure to total health expenditure was $34.4 \%$ in $2012 .{ }^{29}$ For the hip replacements the reimburses is even lower, because the cost of prosthesis is not included in the insurance contents, thus the patients 
have to pay by themselves. Based on this study, hip replacement surgery has a significantly higher mean cost compared with the other treatment method. In general, the health insurance reimbursement for patients with hip fracture is insufficient in China.

\section{CONCLUSION}

The hospitalisation cost of hip fracture has become a great burden to the patients' families. The Chinese medical insurance policy may need further consideration of the demographic and economic factors.

Contributors YW did the data collect and analysis. HC did the text-proofing and revising. DZ directed the data analysis. DZ and PZ were in charge of revision, and were both principal investigators in charge of this study. All authors read and approved the final version for publication.

Funding This study was supported by Chinese National Ministry of Science and Technology 973 Project (No. 2014CB542201) and 863 Project (No. SS2015AA020501), and the National Natural Science Foundation (No. 31571235, 31571236, 31271284).

Competing interests None declared.

Patient consent Not required.

Ethics approval This study was approved by the ethical review committee of the Peking University People's Hospital.

Provenance and peer review Not commissioned; externally peer reviewed.

Data sharing statement № additional data are available.

Open Access This is an Open Access article distributed in accordance with the Creative Commons Attribution Non Commercial (CC BY-NC 4.0) license, which permits others to distribute, remix, adapt, build upon this work non-commercially, and license their derivative works on different terms, provided the original work is properly cited and the use is non-commercial. See: http://creativecommons.org/ licenses/by-nc/4.0/

(C) Article author(s) (or their employer(s) unless otherwise stated in the text of the article) 2018. All rights reserved. No commercial use is permitted unless otherwise expressly granted.

\section{REFERENCES}

1. Cummings SR, Rubin SM, Black D. The future of hip fractures in the United States. Numbers, costs, and potential effects of postmenopausal estrogen. Clin Orthop Relat Res 1990;252:163-6.

2. Owens PL, Russo CA, Spector W, et al. Emergency Department Visits for Injurious Falls among the Elderly, 2006. HCUP Statistical Brief \#80. Rockville, MD: Agency for Healthcare Research and Quality, 2009. http://www.hcup-us.ahrq.gov/reports/statbriefs/sb80. pdf.

3. Kannus P, Parkkari J, Sievänen H, et al. Epidemiology of hip fractures. Bone 1996;18:S57-S63.

4. Robinson CM, Court-Brown CM, McQueen MM, et al. Hip fractures in adults younger than 50 years of age. Epidemiology and results. Clin Orthop Relat Res 1995;312:238-46.

5. Icks A, Arend W, Becker C, et al. Burkhardt Haastert. Incidence of hip fractures in Germany, 1995-2010. Arch Osteoporos 2013;8:140.
6. Dy CJ, McCollister KE, Lubarsky DA, et al. An economic evaluation of a systems-based strategy to expedite surgical treatment of hip fractures. J Bone Joint Surg Am 2011;93:1326-34.

7. Frerichmann U, Raschke MJ, Stöckle U, et al. [Proximal femoral fractures in the elderly. Data from health insurance providers on more than 23 million insured persons-part 2]. Unfallchirurg 2007;110:610-6.

8. Azhar A, Lim C, Kelly E, et al. Cost induced by hip fractures. Ir Med J 2008;101:213-5.

9. Cheng ZA, Lin DK, Liu DB, et al. [A 10-year-review (1998 - 2007) on 3449 cases of osteoporotic hip fractures: trend of hospitalization and inpatient costs]. Zhonghua Liu Xing Bing Xue Za Zhi 2008;29:1128-31.

10. Xia WB, He SL, Xu L, et al. Rapidly increasing rates of hip fracture in Beijing, China. J Bone Miner Res 2012;27:125-9.

11. Yan L, Zhou B, Prentice A, et al. Epidemiological study of hip fracture in Shenyang, People's Republic of China. Bone 1999;24:151-5.

12. Zhang L, Cheng A, Bai Z, et al. Epidemiology of cervical and trochanteric fractures of the proximal femur in 1994 in Tangshan, China. J Bone Miner Metab 2000;18:84-8.

13. Tian FM, Zhang L, Zhao HY, et al. An increase in the incidence of hip fractures in Tangshan, China. Osteoporos Int 2014;25:1321-5.

14. Wang J, Wang Y, Liu WD, et al. Hip fractures in Hefei, China: the Hefei osteoporosis project. J Bone Miner Metab 2014;32:206-14.

15. China Health Promotion Foundation (2008) White Paper China 2008. Osteoporosis a Summary Statement of China. Beijing.

16. Si L, Winzenberg TM, Jiang Q, et al. Projection of osteoporosisrelated fractures and costs in China: 2010-2050. Osteoporos Int 2015;26:1929-37.

17. Lin X, Xiong D, Peng YQ, et al. Epidemiology and management of osteoporosis in the People's Republic of China: current perspectives. Clin Interv Aging 2015;10:1017-33.

18. Leu TH, Chang WC, Lin JC, et al. Incidence and excess mortality of hip fracture in young adults: a nationwide population-based cohort study. BMC Musculoskelet Disord 2016;17:326.

19. stats.gov.cn [Internet]. Annual Data. 2014. http://www.stats.gov.cn/ english/Statisticaldata/AnnualData/

20. moh.gov.cn[Internet]. Number of National Health Institutions at the End of August 2015. http://www.moh.gov.cn/mohwsbwstjxxzx/s7967 /201512/de8a09e26c234154b52638ef372a7152.shtml

21. Wright NC, Looker AC, Saag KG, et al. The recent prevalence of osteoporosis and low bone mass in the United States based on bone mineral density at the femoral neck or lumbar spine. J Bone Miner Res 2014;29:2520-6.

22. Burge R, Dawson-Hughes $\mathrm{B}$, Solomon $\mathrm{DH}$, et al. Incidence and economic burden of osteoporosis-related fractures in the United States, 2005-2025. J Bone Miner Res 2007;22:465-75.

23. Cauley JA, Chalhoub D, Kassem AM, et al. Geographic and ethnic disparities in osteoporotic fractures. Nat Rev Endocrinol 2014;10:338-51.

24. Kanis JA, Odén A, McCloskey EV, et al. A systematic review of hip fracture incidence and probability of fracture worldwide. Osteoporos Int 2012;23:2239-56.

25. Lau EM, Lee JK, Suriwongpaisal P, et al. The incidence of hip fracture in four Asian countries: the Asian Osteoporosis Study (AOS). Osteoporos Int 2001;12:239-43.

26. Tamulaitiene M, Alekna V. Incidence and direct hospitalisation costs of hip fractures in Vilnius, capital of Lithuania, in 2010. BMC Public Health 2012;12:495

27. Kim HY, Ha YC, Kim TY, et al. Healthcare Costs of Osteoporotic Fracture in Korea: Information from the National Health Insurance Claims Database, 2008-2011. J Bone Metab 2017;24:125-33.

28. Weycker D, Li X, Barron R, et al. Hospitalizations for osteoporosisrelated fractures: Economic costs and clinical outcomes. Bone Rep 2016;5:186-91.

29. Ministry of Health. Beijing: China Health Yearbook, 2013.

30. gov.cn [Internet]. Notice of the State Council on Printing and Distributing the "13th Five - Year Plan" Health Care and Health Plan. http://www.gov.cn/zhengce/content/2017-01/10/content 5158488. htm supplemental tables 1229.pdf 